\title{
The Role of Individual and Community Normative Factors: A Multilevel Analysis of Contraceptive Use Among Women in Union in Mali
}

\begin{abstract}
CONTEXT: Unlike in other African countries, the fertility rate in Mali has remained at a relatively high rate of 6.8 births per woman. Little research exists on the role that community norms play in use of family planning, particularly in lowprevalence countries.
\end{abstract}

METHODS: Data on 7,671 women in union from the 2001 Mali Demographic and Health Survey were analyzed using multilevel modeling techniques to assess the effects of individual and community factors on the adoption of modern contraceptive methods.

RESULTS: Only $5 \%$ of women in union were using a modern contraceptive method in 2001. The odds of contraceptive use were elevated among women in the highest wealth quintile, women who approved and whose partner approved of family planning, those who had had recent discussions on family planning with their partner or others and those exposed to family planning messages (odds ratios, 1.4-2.7). At the community level, the odds of modern contraceptive use rose with the proportion of women who were exposed to family planning messages (5.5), and decreased as the mean number of births per woman rose (0.7). In the final model, which included both individual-and community-level factors, the community factors were no longer significant.

CONCLUSIONS: Because approval of family planning and discussion of family planning with partners were shown to be the factors most strongly associated with modern contraceptive use in the multilevel model, programs that seek to increase individual approval and those that teach communication between partners could be particularly helpful to increasing contraceptive use in Mali.

International Family Planning Perspectives, 2008, 34(2):79-88 by Esther B.

Kaggwa,

Nafissatou Diop

and J.Douglas

Storey

Esther B. Kaggwa is doctoral candidate, Department of Population, Family and Reproductive Health, Nafissatou Diop is senior research and evaluation officer, Center for Communication Programs, and J. Douglas Storey is senior advisor, Center for Communication Programs-all at the Johns Hopkins Bloomberg School of Public Health, Baltimore, MD, USA.
With a gross national income of US $\$ 380$ per capita in 2005, Mali is one of the poorest and least developed countries in the world. ${ }^{1}$ Seventy percent of the population is rural. In 2001, as many as $80 \%$ of women had no education, $43 \%$ were in polygamous unions and just $4 \%$ had access to newspapers, television or radio. Additionally, only about one-half of women had consulted a health professional at least once during their last pregnancy. ${ }^{2}$ The country's total fertility rate (TFR) of 6.8 births per woman has remained fairly stable over the past decade and is one of the highest in Africa. ${ }^{2}$ With an infant mortality rate of 120 deaths per 1,000 live births in 2005 and a maternal mortality ratio of 1,200 deaths per 100,000 births in 2000, the country faces significant maternal and child health challenges. ${ }^{3}$

Family planning was introduced in Mali in the late 1960s. In 1967, the Association Malienne pour la Promotion et la Protection de la Famille began a small family planning pilot project in the capital city, Bamako. However, the government of Mali did not establish an official family planning policy until 1972, when a decree authorizing voluntary birth regulation was issued. ${ }^{4}$ Between 1972 and 1990, family planning services were limited to Bamako and other major urban areas. In 1990, however, the government embarked on a family planning promotion campaign. ${ }^{5}$
Nationwide campaigns to promote family planning have continued since then. Despite these efforts, contraceptive use in Mali is still very low. For example, the pill, which is the most widely adopted method, is used by only $3 \%$ of women in union. Yet, by 2001, 76\% of women knew of a modern method of contraception and nearly $29 \%$ were considered to have an unmet need for family planning. ${ }^{2}$

In addition to reporting Mali's high TFR, the 2001 Demographic and Health Survey (DHS) indicates that only $22 \%$ of women in Mali reported an ideal family size of four or fewer children. ${ }^{2}$ In light of the widespread desire for large families and other common pronatalist attitudes, understanding why individuals who practice family planning choose to do so is an important area of research. Additionally, understanding the extent to which a pronatalist environment inhibits adoption of contraceptives is critical in efforts to promote family planning in Mali and other low-prevalence countries.

There is increased interest in exploring the importance of the environment in health behavior changes. Research on this topic generally seeks to look at the relative influences on health behavior of characteristics of the individuals in a community and the environment in which these individuals reside.

A number of theories have been presented to explain 
contraceptive use and fertility regulation in general. In particular, the diffusion of innovations theory has been used to help explain the adoption of family planning in lowprevalence settings. According to the theory, adoption of an idea at the societal level follows a bell-shaped curve. Different types of adopters dominate at different stages of the diffusion curve: Innovators are considered to be the first $3 \%$ of adopters, early adopters are the next 14\%, early majority adopters are the next 34\%, late majority adopters are the next 34\% and laggards are the last 16\%. Individuals in each of these categories have different characteristics-for example, earlier adopters are more open to change than later adopters. The theory posits that at the individual level, adoption of a behavior begins with acquiring knowledge about it, followed by developing a positive attitude toward it, making the decision, implementing it, and finally by confirming or maintaining the behavior. ${ }^{6}$

Research has shown that family planning adopters tend to be more educated than nonadopters. ${ }^{7-12}$ Women in urban areas have been more likely to adopt contraceptives than women in rural areas. ${ }^{10,13,14}$ Although some studies have found no association between contraceptive use and employment, ${ }^{10,14}$ others have found that women working outside the home are more likely to report use than those who do not. ${ }^{8,15}$ Higher socioeconomic status also has been related to adoption of a modern method. ${ }^{7,15}$ Other research has shown that number of children ever born, ${ }^{16}$ discussion of family planning with a partner, ${ }^{10,13,17,18}$ approval of family planning use ${ }^{14,18}$ and desire for no more children $9,17,19$ are associated with higher odds of contraceptive use. Findings on whether ideal family size and family planning use are associated have been mixed. ${ }^{14,19}$

Some studies have shown that the intensity of media exposure does not affect contraceptive use. ${ }^{16}$ However, the majority have demonstrated a positive influence of media and other communication activities on the adoption of contraceptive methods. ${ }^{7,11,13}$

Although there has been significant research on the effect of individual characteristics on contraceptive use, few studies have directly explored the association between fertility-related norms and contraceptive use. The interaction between individual and normative factors also has not been explored. Norms have been defined as "codes of conduct that either prescribe or proscribe behavior that members of a group can enact." ${ }^{20}$ Norms may refer either to what most people do (descriptive) or what people think is acceptable behavior (injunctive).

Research on the influence of norms on contraceptive use is particularly rare in such low-prevalence countries as Mali. In these countries, pronatalist attitudes are common and nonuse of a modern method is the norm. However, even in low-prevalence settings, contraceptive use varies by region and subculture. Analyzing the effect of norms on contraceptive use in such settings is possible if prevalence varies between communities and a common set of values within communities can reasonably be assumed. For example, Kincaid describes how social norms can "influence behavior within relatively bounded local subgroups of a social system rather than the system as a whole." 21 According to this theory, members of the minority subgroup on the edges of the formed boundaries can influence nonadopters in the majority by slowly expanding the boundaries of the minority group and eventually obtaining majority status.

This article explores the different roles that individual and normative factors play in the adoption of modern contraceptives in Mali. In particular, this research seeks to examine individual-level factors associated with contraceptive use among women in union; the community norms associated with contraceptive use; whether community norms have an effect on use of contraceptives, above and beyond women's individual-level characteristics; and whether differences in contraceptive use between communities remain even after the selected individual and community normative factors have been accounted for.

\section{DATA AND METHODS}

This study uses data from the 2001 Mali DHS. The study assumes that a cluster is a community of people who are likely to share common values; it is therefore used as the unit of analysis for the normative environment. Because the survey does not include questions on individual perceptions of community norms, descriptive norms indicating collective behavior and attitudes derived from aggregating individual reports are used.

The data were collected between January and May 2001. Multistage sampling drew 403 clusters from which 12,617 households were successfully selected. The number of women in each cluster ranged from eight to 56 . The refusal rate was 13\% in urban areas and 11\% in rural areas. All consenting women aged 15-49 in each household were interviewed, for a total sample of 12,849. Eighty-three percent of these women were in union, with $82 \%$ married and $1 \%$ cohabiting. Since women who were not married or cohabiting were not asked any questions on partner characteristics, this analysis includes only women in union at the time of the survey.

There has been concern that estimating population averages using a few sampled individuals could lead to biased estimates. ${ }^{22}$ Other errors inherent to small samples also are possible. Using DHS data from Mali and 15 other SubSaharan countries, Kravdal showed that using cluster sizes of at least 25 people produced biases in the average education level of not higher than 10\%. A much lower level of bias was observed for averages based on larger clusters. ${ }^{23}$

For this paper, we first conducted analyses with all 403 clusters and then with only those clusters that had at least 25 individuals. We present results from the subsample of 7,671 women who were residing in the 230 clusters with at least 25 women. The cluster averages for this subsample are more likely to reflect the actual population than the averages from the full sample. The subsample presented here showed lower between-cluster variances and higher covariate standard errors than the full sample. This subsam- 
ple also had a lower proportion of women in union who were using a modern method ( $5 \%$ vs. $7 \%$ ), a higher proportion of women with no education ( $88 \%$ vs. $84 \%$ ), a higher proportion of rural residents (92\% vs. 76\%) and a lower proportion of women who had been exposed to a family planning message ( $53 \%$ vs. $56 \%$ ) than the full sample. However, many of the coefficients from the multivariate models for the two samples were similar, although the standard errors differed.

\section{Variables}

The dependent variable was current use of a modern contraceptive method. Use of a modern method was classified as a dichotomous variable (yes/no). Women were designated as users if they reported use of the pill, the IUD, injections, the diaphragm, female sterilization, the male or female condom, implants, spermicide or the lactational amenorrhea method. All other individuals were classified as nonusers of modern contraception.

Several variables that have been associated with contraceptive use in the literature were included as independent variables. They can be categorized into two sets: individual-level variables and community-level variables.

- Individual-level variables. Individual-level variables in this analysis represent characteristics specific to a woman and her husband or partner. The woman-specific variables examined were age, education, religion, urban or rural residence, region, ethnicity, work outside the home, socioeconomic status, approval of family planning, discussion of family planning with husband or partner, discussion of family planning with people other than the husband or partner and exposure to family planning messages.

Partner-specific variables included are education and approval of family planning. A woman's age was correlated with the number of births and partner's age at a level higher than 0.6. We therefore dropped these two variables and retained woman's age in the model. The decision of which correlated variables to drop was based on the fact that age is important for many reproductive health outcomes, as well as on our interest in examining the influence of age on contraceptive use.

The women were divided into five-year age-groups from 15-19 to 45-49. Socioeconomic status was examined using DHS wealth index scores calculated by weighting and aggregating household assets and normalizing the distribution of the obtained values; these scores are then divided into quintiles. ${ }^{24}$ Women's and partner's education levels were categorized as no education, primary education, or secondary or higher education. The administrative regions of Mali were reclassified as Bamako, Kayes, Koulikoro, Sikasso, Ségou and Northern (Mopti, Tombouctou, Gao and Kidal, which are geographically contiguous and were grouped because of their small sample sizes, particularly for contraceptive users). A woman's approval of family planning was analyzed as a categorical variable: whether the woman approved, did not approve or was not sure if she approved. Partner's approval was based on whether a woman thought her husband or partner approved of family planning. A dichotomous variable indicated whether a woman had talked to her husband or partner about family planning in the past year. Discussion of family planning with other individuals in the past six months was also a dichotomous variable. Exposure to family planning messages was defined as being able to recall a family planning message heard or seen on radio, television or in the newspapers within the past six months, or as having received information through a visit from an outreach worker or a visit to a health facility.

- Community-level variables. The community-level or normative variables examined in this study are proportions or means in the woman's cluster of residence. These variables include the proportion of women desiring a small family size (defined as wanting a family of four or fewer children), the mean number of births per woman in the woman's cluster of residence, the proportion of women who were exposed to a family planning message in the past six months, the proportion of women who approved of family planning and the proportion of women with access to piped water. The latter was defined as either having water piped into one's dwelling, having water piped into one's yard or plot or having access to a public tap. The proportion of women in a cluster who reported discussing family planning with a partner within the past year was correlated with the proportion exposed to a family planning message and was therefore dropped from the models. We chose to retain the proportion of women exposed to family planning messages because we were interested in examining whether differences in community exposure had made a difference in individual use.

To avoid overlap of measures between the two levels of analysis, community-level variables were derived using nonself means or proportions. Each woman was assigned a value representing the average response of all other respondents in her cluster.

\section{Analysis}

Analyses were performed in three steps. First, we calculated descriptive statistics. We then performed bivariate and multivariate analyses to identify associations between contraceptive use and individual- and community-level factors. All analyses were conducted using STATA version 10 and were adjusted for sampling design by including the sampling weights. Multilevel modeling techniques were used to analyze the data. Multilevel modeling provides estimates of the unexplained variance in the outcome that is due to unobserved community factors, generally known as the random effect. ${ }^{25,26}$ Accordingly, all models include a random intercept at the cluster level to capture heterogeneity among clusters. These models assume that within each cluster, contraceptive use follows a binomial distribution. Further, they assume that the cluster means themselves vary according to a normal distribution with a mean (random intercept) and a variance $\left(\mathrm{t}^{2}\right)$. In other words, they assume that the average in each community differs on the basis of community char- 
TABLE 1. Percentage distribution of women in union, by selected characteristics, 2001 Mali Demographic and Health Survey

Characteristic

\section{Contraceptive knowledge}

Knows modern method

Knows only folk or traditional method

Knows no method

Uses modern method

No

Yes

Woman's age

15-19

20-24

25-29

30-34

35-39

40-44

45-49

Wealth quintile

Lowest

Second

Middle

Fourth

Highest

Woman's education

None

Primary

zsecondary

Partner's education

None

Primary

$\geq$ secondary

Religion

Muslim

Other

Region

Bamako

Kayes

Koulikoro

Sikasso

Segou

Northern
$\%$

$(\mathrm{N}=7,671)$

75.0

1.9

23.1

94.7

5.3

10.8

19.2

19.0

16.8

14.2

11.8

8.2

24.4

24.1

23.8

19.4

8.4

87.9

9.2

2.9

84.1

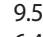

6.4

92.5

7.5

5.4

5.4
15.9

21.1

23.6

17.1
Characteristic

$\%$

$(\mathrm{N}=7,671)$

\section{Residence}

Urban

Rural

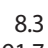

91.7

\section{Ethnicity}

Bambara

Malinke $\quad 10.3$

Peuhl 13.2

Sarakole/Soninke/Marka $\quad 12.2$

Sonrai

Dogon

Tamacheck

Senoufo/Minianka

Bobo

Other

Works outside the home

No

Yes

No. of births

0

$1-2$

$3-4$

$\geq 5$

Woman approves of family planning

No

Yes

Doesn't know

Partner approves of family planning $†$

No

Yes

Doesn't know

Discussed family planning with partner in past yr. No

Yes

Discussed family planning with others in past 6 mos.

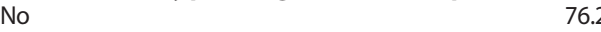

Yes

Exposed to family planning messages in past 6 mos.

$\begin{array}{ll}\text { No } & 47.2 \\ \text { Yes } & 52.8\end{array}$

Total

100.0

†As reported by respondent. Note: Percentages may not total 100.0 because of rounding.

acteristics. The variation in random intercepts is captured as the random effect. A significant random effect indicates unexplained heterogeneity between clusters after other factors in the model are accounted for.*

Multilevel modeling techniques are particularly suited for this kind of analysis. These techniques provide a systematic way of analyzing the influence of factors at different levels on the outcome variable. Such techniques also provide a way to account for similarities among individu-

*The final model is specified as

$$
\operatorname{Logit}\left\{P\left(Y_{i j}=1 \mid \Psi\right)\right\}=\beta_{0}+\beta_{x i j}+\beta_{z i j}+\Psi
$$$$
\Psi \sim \mathrm{N}\left(0, \mathrm{t}^{2}\right)
$$

where $P\left(Y_{i j}\right)$ represents the log odds of women (i) in cluster (j) using a modern method, ${ }_{\text {xij }}$ represents the individual-level covariates, ${ }_{\text {zij }}$ represents the normative factors and $\Psi$ represents the random intercept, which has a variance $\mathrm{t}^{2}$. als residing in the same environment.

Multivariate analyses were conducted using the generalized linear latent and mixed models procedures in STATA, specifying the adaptive quadrature option. ${ }^{27}$ Adaptive quadrature improves the estimates and works well with samples made up of small clusters. ${ }^{28}$ Only variables that were significant at the $10 \%$ level in the bivariate analysis were included in subsequent steps. As a result, religion (Muslim or other) and ethnicity were excluded from multivariate analysis. Four models were estimated in the multivariate analysis. The first, unconditional model included no variables and specified only the random intercept. This model presents the total variance in modern method use among clusters. The second model adds individual-level variables to the unconditional model. The third model adds community-level (but not individual) 
factors, while the fourth model adds both the individual and community factors. In addition to the estimate of the variance of the random intercept, the models also include intraclass correlation coefficients. While the variance of the intercept is a reflection of the heterogeneity between clusters, the intracluster coefficients represent the ratio of the between-cluster variance to the total variance and is a reflection of the level of homogeneity within a cluster. A low intracluster coefficient indicates that a high portion of the variance is due to within-cluster variation. The ratio of the random intercept variance to its standard error can be used as a test of the significance of the between-cluster variance. A ratio that is at least -2 or +2 is considered significant. As a result of including the random intercept, findings from these models represent the association between covariates conditional on the cluster.

\section{RESULTS}

Individual-Level Characteristics

Of all women in union, $75 \%$ knew of a modern contraceptive method, but only $5 \%$ were using one at the time of the survey (Table 1). The pill was the most commonly used method ( $1.8 \%$ of women), followed by injectables
TABLE 2. Means and ranges of community-level characteristics across clusters containing 25 or more women

Characteristic Mean (SD) Range

$\%$ of women reporting use of a modern method

$5.3(6.7) \quad 0.0-38.0$

$\%$ of women with an ideal family size of $\leq 4$ children

$18.0(12.0)$

Mean no. of births

$\%$ of women exposed to family planning messages in past 6 mos.

$4.4(0.77)$

$0.5(0.3)$

$0.0-64.0$

$\%$ of women who approve of family planning

$0.6(0.2)$

2.3-6.7

$\%$ of women with access to piped water

$0.2(0.3)$

$0.0-1.0$

Note: $\mathrm{sd}=$ standard deviation.

(1.7\%) and lactational amenorrhea (1.4\%); each other modern method was used by fewer than $1 \%$ of women (not shown). The majority of women had no education (88\%), were Muslim (93\%) and lived in rural areas (92\%). Eighty-four percent of women were married to men with no education. Two-thirds of the women reported working outside the home, with most working in sales or agriculture (not shown). Almost half (45\%) of the women had had five or more births. Most women (61\%) approved of family planning. Forty-one percent of women did not know if their partner approved of family planning, and close to one-third thought that their husband or partner

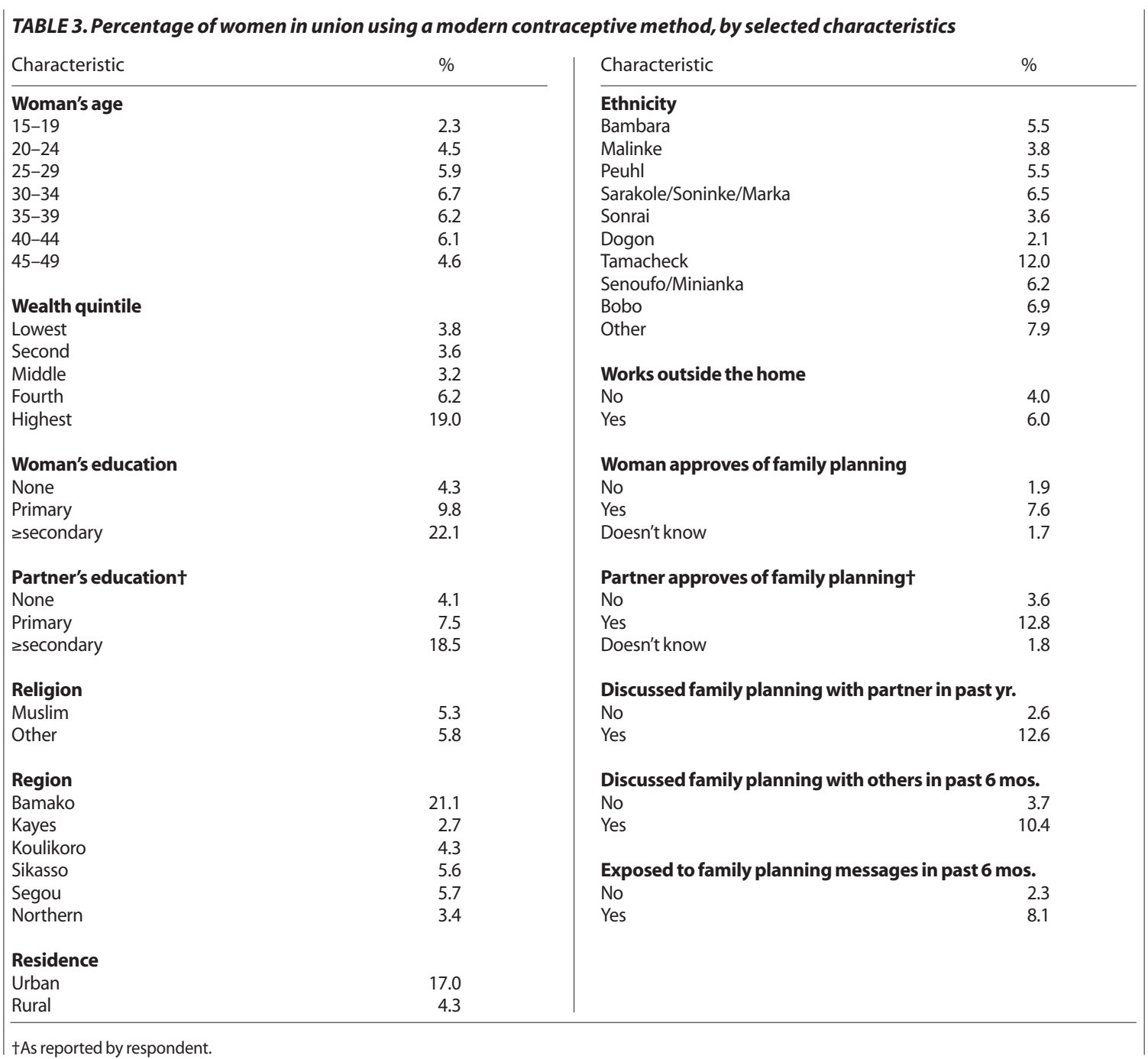


disapproved. A majority (73\%) had not discussed family planning with their partner in the past year or with any other person in the past six months (76\%).

Nearly $53 \%$ of women reported being exposed to a family planning message through radio, television or newspapers or by talking to a health worker. The radio was the most commonly reported medium for family planning information (48\%; not shown), followed by television (21\%) and visits to a health facility (18\%). Only $6 \%$ of women reported getting family planning information from the newspaper and fewer than $10 \%$ had received a message through a home visit from an outreach worker. Seventy percent of nonusers reported not knowing a source for family planning methods.

\section{Community-Level Characteristics}

The data demonstrated significant variations in the normative environment of the respondents (Table 2, page 83). For example, the proportion of women in each cluster using a modern method was $0-38 \%$. The proportion of women with an ideal family size of four or fewer children was $0-64 \%$, while the mean number of live births ranged from 2.3 to 6.7. The range of women reporting exposure to a family planning message, approval of family planning or access to piped water was $0-1 \%$. As indicated by the standard deviations in Table 2, there was significant variation between clusters on these community normative factors.

\section{Bivariate Analysis}

- Demographic characteristics. Four percent of women in the lowest wealth quintile reported use of a modern contraceptive; this was true for $19 \%$ of those in the highest quintile (Table 3, page 83). The proportion of women using a modern method increased with each education level, and was five times as high among women with at least a secondary education as among women with no education. Four percent of women married to men with no education reported using a modern method, while 19\% of those married to man with a secondary education did so. No differences in use were observed by religion; however, use of modern methods did vary by region, ranging from $3 \%$ of women in Kayes to $21 \%$ of those in Bamako. Additionally, the proportion of urban women using a modern method was four times that of rural women ( $17 \%$ vs. 4\%). The percentage of women practicing contraception was highest among the Tamacheck, but varied little among the other ethnic groups. Finally, 4\% of nonworking women and $6 \%$ of those working outside the home were using a modern method.

- Family planning approval, discussion and exposure. The proportion of women using a modern method was $8 \%$ among those approving of family planning and $2 \%$ among those who did not approve. Similarly, the proportion of women using modern methods was more than three times as high among those who thought their partner approved as among those who believed he did not approve (13\% vs. $4 \%$ ). Additionally, 3\% of women who had not discussed family planning with a partner in the past year were using a modern method, compared with 13\% of those who had. Further, the proportion of women using a method was four times as high among those who had been exposed to a family planning message as among those who had not ( $8 \%$ vs. $2 \%$ ).

\section{Multivariate Analysis}

Model 1 indicates a random intercept variance of 0.99 (standard error, 0.20; Table 4). In other words, we estimate that a normally distributed random intercept of contraceptive use has a variance of 0.99 and is significant. However, given that no variables were included, the between-cluster differences in this model could be due to either the observed individual or normative factors or to other unmeasured community factors.

After individual-level variables were controlled for (Model 2), women who worked outside the home were significantly more likely to use a modern method than those who did not (odds ratio, 1.4) and women in the highest wealth quintile were more likely to adopt a method than those in the lowest quintile (2.7). Women aged 25 or older were more likely to use a method than those aged 15-19 (1.8-3.1); there was no difference observed between those aged 15-19 and those aged 20-24. Other factors associated with higher odds of use were family planning approval of the woman (2.2) or her partner (2.1), recent discussion of family planning with partner (2.2) or others (1.4) and exposure to family planning messages (1.6). Although there was no significant difference in use by the woman's education, the odds of use among women whose partner had a primary education and those whose partner had a secondary education were significantly higher than they were among women with uneducated partners ( 1.5 and 1.8 , respectively). The inclusion of individual-level factors reduces the random intercept variance to 0.52 , which is also significant, indicating that although some of the between-cluster differences are attributable to individual characteristics, unexplained variation between clusters remains.

Model 3 shows that, after adjustment for other normative variables, residence in a community with a higher mean number of births was associated with lower odds of modern method use than residence in communities with lower mean numbers of births (odds ratio, 0.7). Residing in a community with a higher proportion of women reporting exposure to a family planning message in the past six months was associated with higher odds of use (5.5). However, the odds of use did not rise with the proportion of women in a community approving of family planning, the proportion desiring a small family or the proportion with access to piped water. Nevertheless, adding the community normative factors to the unconditional model reduced the variance of the random intercept from 0.99 to 0.56 . Thus, these community normative factors explained some, but not all, of the differences between clusters.

In the final model, which included all variables, the effect of the community variables was largely eliminated, but 


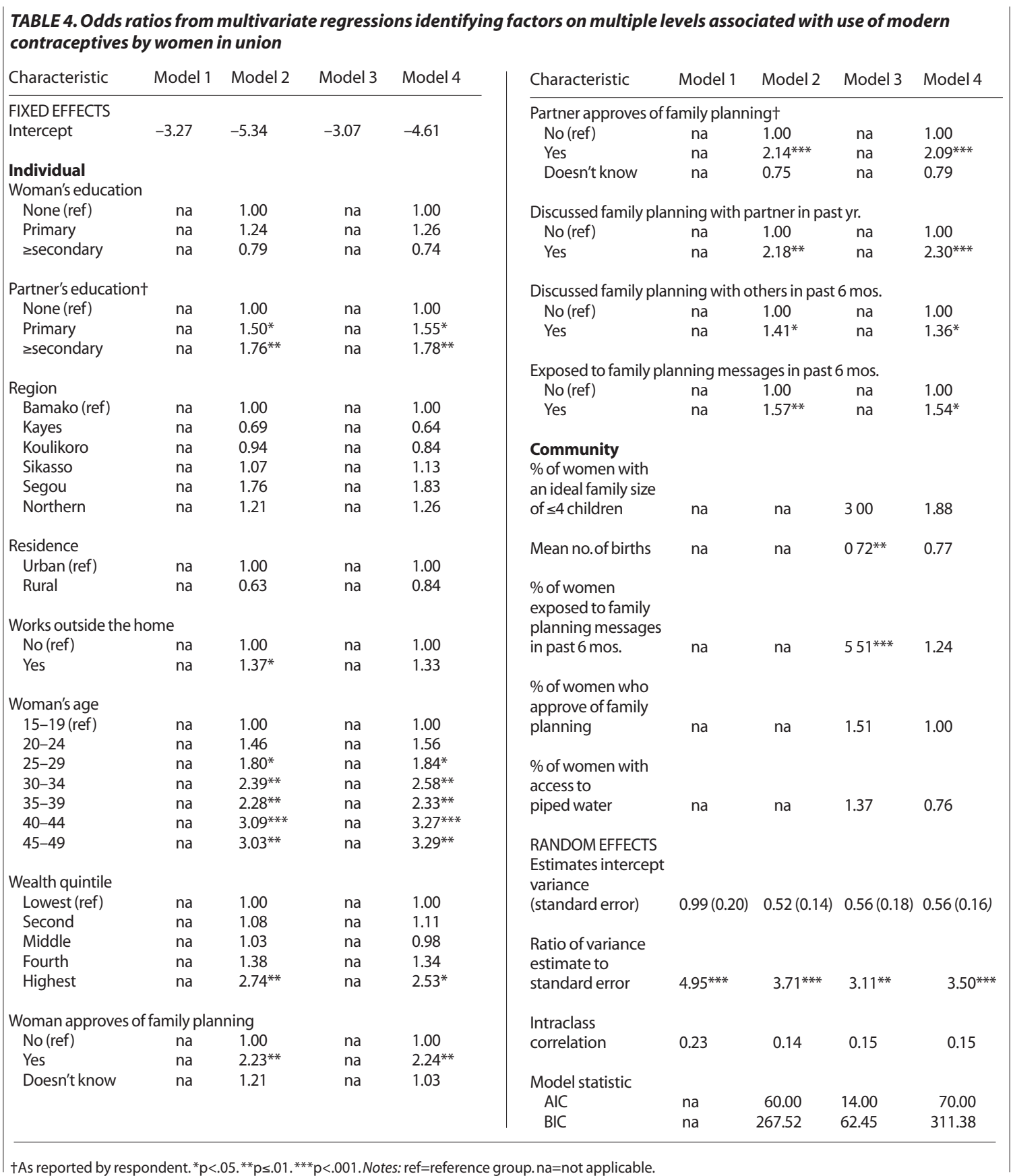

associations between contraceptive use and individual characteristics generally remained similar. In a given cluster, women who were at least 25 years old were significantly more likely to use a modern method than those who were 15-19 years old (odds ratios, 1.8-3.3). Only women in the highest wealth quintile had significantly higher odds of method use than those in the lowest quintile (2.5). Among respondents who approved of family planning, the odds of modern contraceptive use were 2.2 times as high as the odds among those who did not approve, and the odds were significantly higher among those who had recently discussed family planning with their partner or other persons than among those who had not (2.3 and 1.4, respectively). Women who reported hearing a family planning message within the past six months were significantly more likely to be using a modern method than those who did not recall such a message (1.5). Women whose partner had primary schooling or a secondary or higher education were more likely to report contraceptive use than those whose partner had no education (1.6 and 1.8, respectively). Although women who perceived that their husband approved of family planning were more likely to use a method than those who believed he did not (2.1), there was no difference in use between women who were unsure of their partner's attitudes and those who reported partner disapproval.

Among the community factors, only the mean number of births retained even marginal significance $(p=.09)$. Con- 
trolling for community-level variables made little difference in the associations between most individual-level variables and contraceptive use; the exception was work status, which lost significance. The variance of the random intercept remained significant, indicating heterogeneity across clusters even after the individual and community normative factors were accounted for. We conclude, therefore, that there are unobserved community characteristics that are associated with a woman's use of a modern method.

\section{DISCUSSION}

This study showed that spousal discussion about contraception and the woman's approval of family planning had strong associations with use of modern contraceptives. In addition, women were more likely to use a modern method if they believed their partner approved. Interestingly, no significant differences were observed between women in Bamako (the capital city) and those in other regions. As in other research, ${ }^{7,11,13}$ even after all other individual- and community-level variables were taken into account, exposure to family planning messages was still associated with modern contraceptive use.

Our findings differ somewhat from those of several studies that have linked increased levels of education to increased contraceptive use. ${ }^{8,10}$ Although partner's education increased the likelihood of use, a woman's education level was not associated with adoption of a method. It is not clear why education does not have a significant association among the Malian women in our sample; it is possible that pronatalist norms are so entrenched in Mali that even educated women do not find value in using a method before they obtain their desired family size.

Although some community factors were associated with family planning use in the community-only model, none were significant after we controlled for individual-level variables. However, the change in the variance of the random intercept in that model suggests that the community factors did contribute to the variance between clusters. The lack of direct association between contraceptive use and community variables in the full model could be explained in part by the diffusion of innovations theory. Given the low contraceptive prevalence in Mali, one can argue that modern family planning methods are still an innovation, and that the small number of women using modern contraceptives may not yet be sufficient to influence the rest.

Overall, the study found significant variation in use between clusters even after several individual and community normative variables were controlled for. This finding points to the influence of unobserved community characteristics and is consistent with other research indicating that a woman's environment affects whether she adopts a family planning method. ${ }^{29,30}$ Thus, more studies exploring the influence of community factors are needed.

Programs that promote individual approval of family planning as well as teach and model communication between spouses could go a long way toward increasing family planning usage in Mali. Given the innovative nature of contraceptive use in Mali, programs should continue to use interpersonal communication and counseling approaches to promote use of contraceptive methods and emphasize the benefits of planning one's family. The significance of individual exposure to family planning messages in the study suggests that mass media campaigns and community mobilization activities can play an important role in increasing awareness and promoting use of family planning. Further, although our study was not able to measure other community factors, the findings underscore the need to focus on the impact of a woman's environment in campaigns seeking to increase contraceptive use. Such environmental approaches could include increasing access to family planning methods in an area by, for example, adding facilities and using outreach workers.

\section{Limitations}

The study had a number of limitations. First, we were not able to include 173 of the 403 available clusters because they contained fewer than 25 women. As a result, 3,026 women in union from the original sample were dropped from the analysis. In addition, because the DHS did not ask unmarried women questions about partners, women who were not in union at the time of the survey were not included. These findings can therefore be generalized only to Malian women in union. The study also was limited in its measures of the normative environment. The DHS generally does not include questions on what respondents think is acceptable or approved behavior (injunctive norms). Consequently, the normative environment was measured by the average of reported behavior among women in a cluster (descriptive norms). Perceptions of the behaviors of others, as well as opinions about what is considered normative, are more likely to influence behavior than the actual behavior of other people in one's environment. ${ }^{31}$ Another limitation of the study is the potential for endogeneity, since the value of some of the independent variables may be determined or influenced by that of other covariates. For example, exposure to family planning messages might be correlated with community development, which may also be associated with contraceptive use. Finally, because of the cross-sectional nature of our study, we were unable to determine the temporal order of contraceptive use and the independent variables that were controlled for in the models. Studies using longitudinal or panel design are needed to establish causality.

\section{REFERENCES}

1. World Bank Group, Mali data profile, <http://devdata.worldbank. org/external/CPProfile.asp?CCODE=MLI\&PTYPE $=C P>$, accessed May 23, 2007

2. Cellule de Planification et de Statistique du Ministère de la Santé (CPS/MS), Direction Nationale de la Statistique et de l'Informatique (DNSI) and ORC Macro, Enquête Démographique et de Santé au Mali 2001, Calverton, MD, USA: CPS/MS, DNSI and ORC Macro, 2002.

3. World Health Organization, Core health indicators, Mali, <http:// www.who.int/whosis/database/core/core_select_process.cfm> accessed May 28, 2007.

4. Van de Walle F and Maiga M, Family planning in Bamako, Mali, 
International Family Planning Perspectives, 1991, 17(3):84-90 \& 99.

5. Doucoure A et al., The effect of a family planning CBD project in Mali, in: Foreit JR and Frejka T, eds., Family Planning Operations Research: A Book of Readings, New York: Population Council, 1998, pp. 113-118.

6. Oldenburg B and Parcel GS, Diffusion of innovations, in: Glanz K, Rimer BK and Lewis FM, eds., Health Behavior and Health Education: Theory, Research and Practice, third ed., San Francisco, CA, USA: JosseyBass Publisher, 2002, pp. 312-334.

7. Stephenson $\mathrm{R}$ and Tsui AO, Contextual influences on reproductive health service use in Uttar Pradesh, India, Studies in Family Planning, 2002, 33(4):309-320

8. Hogan DP, Berhanu B and Hailemariam A, Household organization, women's autonomy, and contraceptive behavior in southern Ethiopia, Studies in Family Planning, 1999, 30(4):302-314.

9. Dodoo FN, Men matter: additive and interactive gendered preferences and reproductive behavior in Kenya, Demography, 1998, 35(2):229-242.

10. Gage AJ, Women's socioeconomic position and contraceptive behavior in Togo, Studies in Family Planning, 1995, 26(5):264-277.

11. Gupta N, Katende C and Bessinger R, Associations of mass media exposure with family planning attitudes and practices in Uganda, Studies in Family Planning, 2003, 34(1):19-31

12. Bawah AA, Spousal communication and family planning behavior in Navrongo: a longitudinal assessment, Studies in Family Planning, 2002, 33(2):185-194.

13. Jato MN et al., The impact of multimedia family planning promotion on the contraceptive behavior of women in Tanzania, International Family Planning Perspectives, 1999, 25(2):60-67.

14. Salway S, How attitudes toward family planning and discussion between wives and husbands affect contraceptive use in Ghana, International Family Planning Perspectives, 1994, 20(2):44-47 \& 74.

15. Nazar-Beutelspacher A et al., Education and nonuse of contraceptives among poor women in Chiapas, Mexico, International Family Planning Perspectives, 1999, 25(3):132-138.

16. Kane TT et al., The impact of a family planning multimedia campaign in Bamako, Mali, Studies in Family Planning, 1998, 29(3):309323.

17. Sharan M and Valente TW, Spousal communication and family planning adoption: effects of a radio drama serial in Nepal, International Family Planning Perspectives, 2002, 28(1):16-25.

18. Odimegwu CO, Family planning attitudes and use in Nigeria: a factor analysis, International Family Planning Perspectives, 1999, 25(2): 86-91.

19. Lasee A and Becker S, Husband-wife communication about family planning and contraceptive use in Kenya, International Family Planning Perspectives, 1997, 23(1):15-20 \& 33

20. Rimal RN and Real K, Understanding the influence of perceived norms on behaviors, Communication Theory, 2003, 13(2):184-203.

21. Kincaid DL, From innovation to social norm: bounded normative influence, Journal of Health Communication, 2004, 9(Suppl. 1):37-57.

22. Sampson RJ, Raudenbush SW and Earls F, Neighborhoods and violent crime: a multilevel study of collective efficacy, Science, 1997, 277(5328):918-924.

23. Kravdal $\varnothing$, A simulation-based assessment of the bias produced when using averages from small DHS clusters as contextual variables in multilevel models, Demographic Research, 2006, 15:1-20.

24. Rutstein SO and Johnson $\mathrm{K}$, The DHS Wealth Index, DHS Comparative Reports, Calverton, MD, USA: ORC Macro, 2004, No. 6.

25. Bingenheimer JB and Raudenbush SW, Statistical and substantive inferences in public health: issues in the application of multilevel models, Annual Review of Public Health, 2004, 25:53-77.

26. Guo $\mathrm{G}$ and Zhao H, Multilevel modeling for binary data, Annual
Review of Sociology, 2000, 26:441-462.

27. Rabe-Hesketh S, Skrondal A and Pickles A, GLLAMM Manual, U.C. Berkeley Division of Biostatistics Working Paper Series, Berkeley, CA, USA: University of California, Berkeley, 2004, No. 160.

28. Rabe-Hesketh S, Skrondal A and Pickles A, Reliable estimation of generalized linear mixed models using adaptive quadrature, Stata Journal, 2002, 2(1):1-21.

29. Stephenson R, Beke A and Tshibangu D, Contextual influences on contraceptive use in the Eastern Cape, South Africa, Health E Place, 2008 (forthcoming).

30. Stephenson R et al., Contextual influences on modern contraceptive use in Sub-Saharan Africa, American Journal of Public Health, 2007, 97(7):1233-1240

31. Kallgren CA, Reno RR and Cialdini RB, A focus theory of normative conduct: when norms do and do not affect behavior, Personality and Social Psychology Bulletin, 2000, 26(8):1002-1012.

\section{RESUMEN}

Contexto: A diferencia de otros países africanos, la tasa de fecundidad en Mali ha permanecido a un nivel relativamente alto de 6.8 nacimientos por mujer. Hay poca investigación sobre el rol que las normas de la comunidad juegan en el uso de planificación familiar, especialmente en países de baja prevalencia del uso.

Métodos: Se analizó un conjunto de datos de la Encuesta de Demografía y Salud de Mali 2001 sobre 7,671 mujeres en unión, utilizando técnicas de modelación multinivel para evaluar los efectos de factores individuales y comunitarios en la adopción de métodos de anticoncepción moderna.

Resultados: Solamente 5\% de las mujeres en unión estaban usando un método de anticoncepción moderna en 2001. Las probabilidades de uso de anticonceptivos eran elevadas en mujeres del quintil más alto de riqueza, en mujeres que aprobaban y cuyas parejas aprobaban la planificación familiar, en quienes tuvieron conversaciones recientes sobre planificación familiar con sus parejas u otras personas, y en quienes estuvieron expuestas a mensajes de planificación familiar (razones de momios, 1.4-2.7). A nivel de la comunidad, las probabilidades de uso aumentaron con la proporción de mujeres que estuvieron expuestas a mensajes de planificación familiar (5.5); y disminuyeron al aumentar el número medio de nacimientos por mujer (0.7). En el modelo final que incluye tanto factores individuales como de nivel comunitario, los factores comunitarios ya no fueron significativos.

Conclusiones: Debido a que en el modelo multinivel se mostró que la aprobación de la planificación familiar y la posibilidad de conversar sobre ello en pareja eran los factores más fuertemente asociados con el uso de anticonceptivos modernos, los programas que buscan aumentar la aprobación individual y los que enseñan comunicación en la pareja podrían ser de especial ayuda para aumentar el uso de anticoncepción en Malí.

\section{RÉSUMÉ}

Contexte: Contrairement à d'autres pays d'Afrique, l'indice de fécondité du Mali demeure relativement élevé, à 6,8 naissances par femme. La recherche est rare sur le rôle des normes de la communauté dans la pratique de la planification familiale, surtout dans les pays à faible prévalence. 
Méthodes: Les données relatives à 7.671 femmes en union issues de l'Enquête démographique et de santé malienne de 2001, ont été analysées par techniques de modélisation multiniveaux afin d'évaluer les effets de facteurs individuels et communautaires sur l'adoption de méthodes contraceptives modernes.

Résultats: Cinq pour cent seulement des femmes en union pratiquaient une méthode contraceptive moderne en 2001. La probabilité était élevée parmi les femmes du quintile de richesse supérieur, celles favorables ou dont le partenaire était favorable à la planification familiale, celles qui avaient récemment discuté la planification familiale avec leur partenaire ou d'autres interlocuteurs et celles exposées aux messages de planification familiale (rapports de probabilités, 1,4-2,7). Au niveau de la communauté, la probabilité de recours à la contraception moderne s'accroît avec la proportion de femmes exposées aux messages de planification familiale $(5,5)$ et diminue à mesure que le nombre moyen de naissances par femme augmente $(0,7)$. Dans le modèle final faisant état des facteurs individuels et communautaires, ces derniers ne sont plus significatifs.

Conclusions: L'analyse a démontré que l'approbation de la planification familiale et sa discussion avec le partenaire sont les facteurs le plus fortement associés à la pratique contraceptive moderne dans le modèle multiniveaux. Les programmes qui visent à accroître l'approbation individuelle et ceux qui apprennent aux partenaires à communiquer pourraient doncêtre particulièrement utiles à l'accroissement de la pratique contraceptive au Mali.

\section{Acknowledgments}

The authors wish to thank Stella Babalola and Michelle Hindin for providing commentary on an earlier draft of this article.

Author contact:ekaggwa@jhsph.edu 